\title{
Some aspects of the metabolism and biochemistry of vitamin A
}

\author{
By J. N. Thompson (British Egg Marketing Board Fellow in Poultry \\ RESEARCH), Department of Biochemistry, University of Liverpool
}

Important aspects of the study of vitamin $A$ are the identification of its 'active form' and elucidation of its mode of action at the enzymic level. Some recent findings concerning the metabolism of vitamin A and the effect of vitamin A metabolites on enzyme systems are reviewed.

\section{The metabolism of vitamin $A$}

Formation of retinol, retinyl esters and retinal. Dietary provitamins and vitamin A are sources of tissue deposits of retinol, retinyl esters and retinal; the latter substances constitute a storage and transport system (Ganguly, 1960) which allows a continuous supply of the active form of the vitamin to be provided at whatever site it is required. The alcohol, aldehyde and esters are readily interconverted enzymically, and intake of one particular form of the vitamin in the diet is followed by in vivo conversion into the others.

Oxidation of retinol to retinal is catalysed by alcohol dehydrogenase enzymes of wide distribution (Glover, Goodwin \& Morton, I948; Wald \& Hubbard, 1948-9; Bliss, I95 I; Futterman \& Saslaw, 196r). In rod outer segments, the reduction of retinal utilizes principally NADPH as cofactor (Futterman, 1963).

Retinal is the active form of vitamin $A$ in vision, being the prosthetic group of the visual pigments (Hubbard \& Kropf, 1959); its occurrence outside the retina implies that it might have other unsuspected functions (Plack, Kon \& Thompson, I958, 1959; Pollard \& Bieri, 1959; Plack, 1960; Winterstein \& Hegedüs, 1960). The role of vitamin $A$ in vision has been reviewed recently (Wald, 1960) and will not be considered here. This aspect of vitamin A biochemistry and metabolism, however, is probably 'better understood by far than any other major function of the fat soluble vitamins' (Pitt \& Morton, 1962).

Formation of retinoic acid. Retinoic acid and its esters were first obtained during attempts at the chemical synthesis of retinol (Heilbron, Jones, Lowe \& Wright, 1936; van Dorp \& Arens, 1946a). Subsequent discovery of the comparatively high biological activity of the free acid in rat growth tests (van Dorp \& Arens, 1946b) without its being reduced in vivo to retinol (Arens \& van Dorp, 1946; Sharman, I949) encouraged the speculation that retinoic acid was a metabolite of retinol, and was a precursor of, or was itself, the systemically active form of vitamin A (Dowling \& Wald, I960).

It has been shown that enzymic oxidation of retinal to retinoic acid can occur in vitro (Futterman, I962; Mahadevan, Murthy \& Ganguly, r962; Elder \& Topper, r 962 ), and thus the suggested formation of retinoic acid in vivo is biochemically feasible; whether the biological effect of this conversion is quantitatively significant, however, remains in doubt. Dmitrovsky ( 1961 ) detected retinoic acid in the jejunum of rats given by mouth $20 \mathrm{mg}$ retinal; but retinoic acid could not be detected in intestine, blood or liver of chicks given 3 mg retinal (Krishnamurthy, Bieri \& Andrews, 
I 963), and attempts to trap radioactivity in unlabelled retinoic acid after administering $\left[{ }^{14} \mathrm{C}\right] \mathrm{retinol}$ have not been successful (Wolf \& Johnson, I960a; Varandani, Wright, Wolf \& Johnson, 1960; Wright, 1961). Failure to detect retinoic acid might have resulted from its rapid metabolism; also much of the administered retinol or retinal would be stored as retinyl esters and would thus be protected from oxidation.

Formation of retinoic acid from retinol would only need to occur slowly even if it is an essential stage in the production of an 'active form'. In preventing overt deficiency lesions, retinoic acid is almost as active as retinol, providing the most efficient methods of administration are used for each substance (van Dorp \& Arens, I $946 b$ ). It has been shown that in the chick and rat the biological activity of all-trans retinoic acid is approximately equal to that of all-trans retinyl acetate, and the other isomers in each instance are less effective (Murray, I962; de Man, van Leeuwen \& Roborgh, I964).

The difference in activity between retinoic acid and retinol in preventing overt deficiency lesions is small and can be related to differences in absorption, stability and transport. Malathi, Subba Rao, Seshadri Sastry \& Ganguly (1963) measured the changes in body-weight in vitamin A-deficient rats given retinoic acid in a curative test, and concluded that retinoic acid was $141 \%$ as active as retinyl acetate when injected intraperitoneally. However, their data reveal that the differences observed were due more to the poor utilization of the retinyl acetate after intraperitoneal injection (Moore, 1957) than to any real superiority of the acid.

It has been suggested that much of the toxicity of retinol to animals results from oxidation to the acid (Thompson \& Pitt, 1960). If the availability of retinal is the rate-limiting factor in the formation of the acid, abnormal increases in tissue levels of the aldehyde after ingestion of large amounts of vitamin A might stimulate production of retinoic acid, and so precipitate signs of hypervitaminosis. As might be predicted from this theory, retinal is more toxic than retinol, but less toxic than retinoic acid (Harris, 1960). The potency of retinoic acid in inducing signs of hypervitaminosis $A$ is much in excess of that of retinol (Thompson \& Pitt, r96I) and the lesions observed in young rats given from 4 to $10 \mathrm{mg}$ retinoic acid daily are more severe than can be obtained with retinol at any dose level. Similarly, retinoic acid is more toxic than retinol for Xenopus laevis (Weissmann, Bell \& Thomas, 1963) and in chick limb rudiments in tissue culture (Fell, Dingle \& Webb, 1962). In incubating chicken eggs, retinoic acid is at least 500 times as toxic as retinol (Thompson, Howell, Pitt \& Houghton, 1965). As little as $0.5 \mu \mathrm{g}$ retinoic acid when injected into the egg prevents development of the embryo.

The activity of retinoic acid in preventing overt deficiency signs and in producing hypervitaminosis contrasts with its total inability to function in vision (Dowling \& Wald, r 960), and in reproduction (Thompson, Howell \& Pitt, 1964). The inactivity of retinoic acid in vision can be satisfactorily related to the irreversible nature of the enzymic oxidation of retinal, and the resulting inability of animals to form visual pigments (Moore, 1953). When rats are given vitamin A-deficient diets containing retinoic acid they eventually become blind, as their stores of retinol and retinal in the eye are exhausted. Dowling \& Wald (1960) suggested that the visual function of 
vitamin A was special, being essentially the provision of retinal, whereas the remaining roles were served by formation of retinoic acid or after further metabolism. The inability of retinoic acid to function in reproduction adds complications to the scheme: it must be assumed that the acid has to be formed in situ in reproductive tissues, or alternatively that reproduction is another special function requiring retinol or retinal specifically.

The argument that production of retinoic acid is essential during the normal biological actions of retinol has been neither disproved nor unequivocally confirmed; however, the experimental evidence is, as yet, compatible with the view that retinoic acid is a normal precursor of some of the active forms of vitamin A.

Metabolism of retinol and retinoic acid. Attempts have been made to follow the metabolism of $\left[{ }^{14} \mathrm{C}\right]$ retinol. Wolf, Kahn \& Johnson (1957) injected $\left[{ }^{2-14} \mathrm{C}\right]$ retinol into rats, measured the distribution of activity among non-saponifiable, saponifiable and water-soluble fractions of tissue and excreta, and discovered an abundance of unidentified 'metabolites'. Experiments on subcellular distribution of radioactivity and in vitro metabolism of $\left[{ }^{14} \mathrm{C}\right]$ retinyl acetate gave similarly inconclusive results (Wolf \& Johnson, 1960a).

Early studies of the metabolism of retinoic acid revealed that this substance, in contrast to the alcohol, rapidly disappeared from the tissue of animals, even when administered in large amounts. Similarly, the biological effects of single doses were short-lived (Sharman, I949; Dowling \& Wald, r960; Redfearn, 1960; Malathi et al. 1963). After the initial failures to find administered retinoic acid in tissues of intact animals, it has been detected in human blood after giving $1 \cdot 5 \cdots 3.0 \mathrm{mg} / \mathrm{kg}$ body-weight (Jurkowitz, 1962). Labelled retinoic acid has been administered to chicks and has subsequently been recovered from their tissues (Krishnamurthy et al. 1963). More recently, contents of retinoic acid have been measured quantitatively in liver and fat from rats dosed with unlabelled material (Weitzel \& Schnapka, I964). After Io mg doses a maximum content of $8 \mu \mathrm{g} / \mathrm{g}$ was found after $2 \mathrm{~h}$. The fall in concentration of retinoic acid in liver after $2 \mathrm{~h}$ appears to be paralleled by a fall in the level in blood (Nelson, Dehority \& Teague, ${ }^{1963}$ ).

Labelled retinoic acid and retinol are metabolized in rat liver to water-soluble substances which are carried in the bile to the intestine, and then recirculated (Zachman \& Olson, I964, I965). The chemical structure of these metabolites has not yet been revealed, nor is their physiological significance clear. Labelled substances with biological activity have been obtained from animals given labelled retinoic acid (Rogers, Chang \& Johnson, 1963 ; Sundaresan \& Wolf, 1963; Zile \& DeLuca, 1964).

More detailed descriptions of the isolation and biological assay of one acidic metabolite have been given in preliminary form (Yagishita, Sundaresan \& Wolf, I964). This substance, termed 'compound 5', has been claimed to promote the growth of vitamin A-deficient rats, and is considered to be neither identical with retinoic acid nor converted back into the acid in vivo. Retinoic acid loses its side-chain terminal carbon atom during the formation of this metabolite, which is suggested to possess two double bonds conjugated with a carboxyl group, and an additional hydroxyl group. 


\section{The mode of action of vitamin $A$}

The complex pathology of vitamin A deficiency implies that vitamin A has more than one biological role; a correspondingly diverse range of theories concerning the fundamental mode of action has been suggested. Recently attention has been directed towards two biochemical systems in which vitamin A metabolites might have a direct effect: these are the activation of sulphate and the metabolism of steroid hormones.

Role of vitamin A in sulphur metabolism. Epithelial metaplasia in its various manifestations is largely responsible for the debilitation and death of many species severely deficient in vitamin A, and the influence of vitamin A on epithelial tissues is usually considered to be its major systemic effect. In tissue culture experiments retinol induces a mucus-secreting type of epithelium in place of keratinized tissue, and similar changes are induced by local application of the vitamin to intact animals. Retinol thus directly affects the metabolism of some epithelial tissues: if the true active form is a metabolite of retinol, the epithelial tissues must possess the necessary enzyme systems to produce it.

Recently one aspect of the metabolism of mucus-secreting epithelia, the formation of mucopolysaccharides, has been shown to be affected by vitamin A deficiency. In vitro systems that formed mucopolysaccharides were prepared from segments or homogenates of rat and pig colon (Wolf \& Johnson, i 9606 ). It was discovered that preparations obtained from vitamin A-deficient animals formed less mucopolysaccharide than control ones, but the addition of retinol to the incubation mixtures restored their activity to the normal level. After demonstrating a similar effect in preparations carrying out only the later stages of mucopolysaccharide biosynthesis, it was concluded that retinol did not affect the preliminary reactions, i.e. the formation and acetylation of hexosamines, their conversion into uridine diphosphoacetylhexosamines, and the oxidation of uridine diphosphoglucose to uridine diphosphoglucuronic acid. The polymerization of the uridine nucleotides and the transfer of sulphate to the polymer thus remained as the possible sources of the vitamin A action.

Pig colon homogenates were obtained which synthesized labelled mucopolysaccharides from labelled sulphate and glucose. After centrifugation to remove nuclei, mitochondria and microsomes, the synthesizing activity was found in the supernatant solution, and could be precipitated at $\mathrm{pH}_{5}$; perhaps significantly, the ' $\mathrm{pH} 5$ enzymes' contained half the mucosal vitamin A. When obtained from deficient animals the activity of the enzyme was below normal, but was restored on in vitro addition of vitamin A (Wolf, Varandani \& Johnson, 1961).

In rat colon preparations it was shown that vitamin A deficiency affected the activation of sulphate, i.e. the formation of $3^{\prime}$-phosphoadenosine- $5^{\prime}$-phosphosulphate (Varandani, Wolf \& Johnson, I960). Investigation revealed that the first stage of the process, the reaction of ATP with sulphate, catalysed by sulphurylase, was very much inhibited in deficient animals (Sundaresan \& Wolf, 1963).

When enzyme was prepared from tissues of animals given $\left[{ }^{14} \mathrm{C}\right] \mathrm{retinoic}$ acid, labelled material could be extracted from it with butanol. Butanol extracts of enzyme 
from normal rats restored much of the impaired activity of enzymes obtained from vitamin A-deficient animals. Unchanged retinoic acid and retinol were inactive in this respect.

A retinoic acid metabolite was also obtained from rat stomach which stimulated the impaired sulphate activation previously observed in tissue from deficient animals, whereas retinol and retinoic acid were found to be inactive (Rogers et al. 1963).

Wolf, Bergan \& Sundaresan ( 1963 ) obtained a mucopolysaccharide-synthesizing system in a particulate fraction. Preparations from deficient animals had low activity, which again could be restored to normal by an acidic metabolite of retinoic acid. Retinol had only feeble stimulating effect.

These preliminary communications indicate that metabolites of retinol and retinoic acid, but not the unchanged compounds, have perhaps a cofactor role in the activation of sulphate. This reaction is of fundamental importance in the biosynthesis of many sulphur-containing substances, and a fall in activity might have serious physiological consequences, not only because of reduced formation of the sulphated polysaccharides, but also from effects on other systems utilizing sulphated intermediates. Impaired sulphate activation is compatible with the reduced activity of enzyme systems sulphurylating phenols when prepared from tissues of vitamin A-deficient rats (Subba Rao, Seshadri Sastry \& Ganguly, 1963; Subba Rao \& Ganguly, 1964). In these experiments, however, in vitro addition of retinol raised the activity towards the normal level.

Role of vitamin $A$ in steroid hormone production. Since the discovery of histological abnormalities in the adrenals of vitamin A-deficient rats (Lowe, Morton \& Harrison, 1953), many lines of investigation have suggested that vitamin A deficiency affects steroid hormone production. There are several mechanisms by which vitamin A deficiency could affect adrenal function indirectly. Thus, for example, an effect of deficiency in the activation of sulphate might interfere with aspects of steroid metabolism which involve sulphated intermediates (Roberts, Bandi, Calvin, Drucker \& Lieberman, 1964).

More direct effects have been suggested by Grangaud and coworkers who claim that vitamin A deficiency affects progesterone biosynthesis (Grangaud \& Conquy, I95 $8 a$; Grangaud \& Nicol, r959). Injections of progesterone into female rats were found to oppose to some extent the effects of vitamin A deficiency; weight increases continued, xerophthalmia and permanent vaginal cornification were delayed and survival was prolonged (Grangaud \& Conquy, 1958b). Androstenedione and progesterone stimulated growth in male and female rats given a vitamin A-deficient diet. Their respective precursors, dehydroepiandrosterone and pregnenolone (Grangaud, Conquy \& Nicol, 1959, I961) did not have beneficial effects, suggesting that each conversion was the site of a metabolic block in vitamin A deficiency.

From experiments with intact animals and with adrenal tissue in vitro, evidence has been obtained that the conversion of deoxycorticosterone into corticosterone is impaired in deficiency (Johnson \& Wolf, I960). In adrenal tissue from severely deficient animals, many stages of steroid hormone production were found to be inhibited, including the formation of cholesterol, progesterone and deoxycorti- 
costerone. The conversion of deoxycorticosterone into corticosterone, however, was the only step inhibited in mildly deficient animals. In vivo and in vitro, retinol and retinoic acid were found to stimulate formation of corticosterone in the adrenal (Wu Chang \& Willis, 1963).

\section{Conclusion}

Many of the findings discussed above have only been reported in preliminary form, and some have not been confirmed in other laboratories. Thus Pasternak, Humphries \& Pirie ( 1963 ) failed to demonstrate reduced activation of sulphate in extracts of cornea and colon from vitamin A-deficient animals.

Reduced rates of sulphate activation and steroid hormone production in tissues from vitamin A-deficienct animals are not in themselves necessarily fundamentally significant findings: such changes might even be expected as biochemical manifestations of the histological abnormalities.

The crucial experiments are those in which vitamin $A$ or its metabolites restored and stimulated the activity of enzymes in vitro. Also of importance are the claims that metabolites of retinoic acid are apparantly incorporated, in the intact animal, into the enzymes as cofactors.

The implications of the experiments discussed suggest three important questions: first, is retinol metabolized to an active form before it exerts its normal biological actions; secondly, is retinoic acid an intermediate in this process; and thirdly does vitamin $\mathrm{A}$ have more than one non-visual biochemical role?

Finally, it might be questioned whether all the diverse biochemical properties of vitamin $A$ that have been demonstrated in the laboratory are necessarily of importance to the well-being of the animal requiring vitamin $A$ in its diet.

\section{REFERENCES}

Arens, J. F. \& van Dorp, D. A. (1946). Nature, Lond., 158, 622.

Bliss, A. F. (1951). Arch. Biochem. Biophys. 31, 197.

de Man, T. J., van Leeuwen, P. H. \& Roborgh, J. R. (1964). Nature, Lond., 20x, 77.

Dmitrovsky, A. A. (196r). Biokhimiya, 26, 126.

Dowling, J. E. \& Wald, G. (1960). Vitam. \& Horm. 18, 515.

Elder, T. D. \& Topper, Y. J. (1962). Biochim. biophys. Acta, 64, 430 .

Fell, H. B., Dingle, J. T. \& Webb, M. (r962). Biochem. Y. 83, 63.

Futterman, S. (1962). F. biol. Chem. 237, 677.

Futterman, S. (1963). F. biol. Chem. 238, 1145 .

Futterman, S. \& Saslaw, L. D. (1961). J. biol. Chem. 236, 1652.

Ganguly, J. (1960). Vitam. छ Horm. 18, 387.

Glover, J., Goodwin, T. W. \& Morton, R. A. (1948). Biochem. F. 43, 109.

Grangaud, R. \& Conquy, T. (1958a). Algérie méd. 62, 987.

Grangaud, R. \& Conquy, T. (1958b). C.R. Acad. Sci., Paris, 246, 3274.

Grangaud, R., Conquy, T. \& Nicol, M. (1 959). C.R. Acad. Sci., Paris, 249, 93 I.

Grangaus, R., Conquy, T. \& Nicol, M. (1961). C.R. Soc. Biol., Paris, 155, 476.

Grangaud, R. \& Nicol, M. (เ959). Algérie méd. 63, 83 r.

Harris, P. L. (1960). Vitam. E Horm. x8, 34I.

Heilbron, I. M., Jones, W. E., Lowe, A. \& Wright, H. R. (1936). \%. chem. Soc. p. 56 I.

Hubbard, R. \& Kropf, A. (1959). Ann. N.Y. Acad. Sci. 81, 388.

Johnson, B. C. \& Wolf, G. (I960). Vitam. \& Horm. 18, 457.

Jurkowitz, L. (1962). Arch. Biochem. Biophys. 98, 337.

Krishnamurthy, S., Bieri, J. G. \& Andrews, E. L. (I963). F. Nutr. 79, 503.

Lowe, J. S., Morton, R. A. \& Harrison, R. G. (1953). Nature, Lond., 172, 7 I6.

Mahadevan, S., Murthy, S, K. \& Ganguly, J. (1962). Biochem. F. 85, 326. 
Malathi, P., Subba Rao, K., Seshadri Sastry, P. \& Ganguly, J. (1963). Biochem. 7. 87, 305.

Moore, T. (1953). In Symposium on Nutrition, pp. 28-70. [Herriot, R. M., editor.] Baltimore, Md: Johns Hopkins Press.

Moore, 'T. (1957). Vitamin A, p. 204. Amsterdam: Elsevier.

Murray, T. K. (1962). Proc. Soc. exp. Binl., N.Y., 111, 609.

Nelson, E. C., Dehority, B. A. \& Teague, H. S. (1963). Fed. Proc. 22, 434.

Pasternak, C. A., Humphries, S. K. \& Pirie, A. (1963). Biochem. Y. 86, $3^{82 .}$

Pitt, G. A. J. \& Morton, R. A. (1962). Annu. Rev. Biochem. 31, 491.

Plack, P. A. (1960). Nature, Lond., 186, 234.

Plack, P. A., Kon, S. K. \& Thompson, S. Y. (1958). Biochem. F. 68, 2 P.

Plack, P. A., Kon, S. K. \& Thompson, S. Y. (I959). Biochem. F. 7r, 467.

Pollard, C. J. \& Bieri, J. G. (1959). Biochim. biophys. Acta, 31, 558.

Redfearn, E. R. (1 960). Arch. Biochem. Biophys. 91, 226.

Roberts, K. D., Bandi, L., Calvin, H. I., Drucker, W. D. \& Lieberman, S. (1964). Biochemistry, N.Y., 3,1983 .

Rogers, W. E., Chang, M. L. \& Johnson, B. C. (r963). Fed. Proc. 22, 433.

Sharman, I. M. (I949). Brit. F. Nutr. 3, viii.

Subba Rao, K. \& Ganguly, J. (1964). Biochem. F. 90, 104.

Subba Rao, K., Seshadri Sastry, P. \& Ganguly, J. (1963). Biochem. F. 87, 3 I 2.

Sundaresan, P. R. \& Wolf, G. (1963). Fed. Proc. 22, 293.

Thompson, J. N., Howell, J. McC. \& Pitt, G. A. J. (1964). Proc. roy. Soc. B, 159, 510.

Thompson, J. N., Howell, J. McC., Pitt, G. A. J. \& Houghton, C. I. (1965). Nature, Lond., 205, 1006,

Thompson, J. N. \& Pitt, G. A. J. (1960). Nature, Lond., 188, 672.

Thompson, J. N. \& Pitt, G. A. J. (I961). Biochem. F. 79, 33P.

van Dorp, D. A. \& Arens, J. F. (1946a). Rec. Trav. chim. Pays-Bas, 65, 338.

van Dorp, D. A. \& Arens, J. F. (1946b). Nature, Lond., 158, 60.

Varandani, P. 'T., Wolf, G. \& Johnson, B. C. ( (960). Biochem. biophys. Res. Commun. 3, 97.

Varandani, P. T., Wright, G. J., Wolf, G. \& Johnson, B. C. (I960). Fed. Proc. 20, 242.

Wald, G. (1960). Vitam. $\mathscr{6}$ Horm. 18, 417.

Wald, G. \& Hubbard, R. '(1948-9). Y. gen. Physiol. 32, 367.

Weissmann, G., Bell, E. \& Thomas, L. (1963). Amer. F. Path. 42, 57 I.

Weitzel, G. \& Schnapka, G. (1964). Schweiz. med. Wschr. 94, 218.

Winterstein, A. \& Hegedüs, B. (1960). Hoppe-Seyl. Z. 321, 97.

Wolf, G., Bergan, J. G. \& Sundaresan, P. R. (1963). Biochim. biophys. Acta, 69, 524.

Wolf, G. \& Johnson, B. C. (1960a). Vitam. E Horm. 18, 403.

Wolf, G. \& Johnson, B. C. (1960b). Vitam. छ Horm. 18, 439.

Wolf, G., Kahn, S. G. \& Johnson, B. C. (1957). F. Amer. chem. Soc. 79, 1208.

Wolf, G., Varandani, P. T. \& Johnson, B. C. (1961). Biochim. biophys. Acta, 46, 59.

Wright, G. J. (I96I). Amer. F. clin. Nutr. 9, no. 4, part 2, p.26.

Wu Chang, M. L. \& Willis, E. (I963). Fed. Proc. 22, 434.

Yagishita, K., Sundaresan, P. R. \& Wolf, G. (1964). Nature, Lond., 203, 410.

Zachman, R. D. \& Olson, J. A. (1964). Nature, Lond., $201,1222$.

Zachman, R. D. \& Olson, J. A. (1965). F. Lipid Res. 6, 27.

Zile, M. \& DeLuca, H. F. (I 964). Fed. Proc. 23, 294.

\title{
The effect of vitamin $A$ on the breakdown and synthesis of intercellular material in skeletal tissue in organ culture
}

\author{
By Honor B. Fell (Royal Society Researci Professor), Strangeways Research \\ Laboratory, Cambridge
}

In a previous talk to the Society in 1959, I gave an account of our studies of the direct action of vitamin A on tissue structure (Fell, 1960); the present paper deals with the sequel to this early work.

My interest in the action of vitamin A was aroused by the late Sir Edward Mellanby. It is known that, when animals are fed on a diet containing excess of vitamin $A$, their bones undergo severe resorption often accompanied by spontaneous 